\title{
The Potential Role of Flexible Transport Services in Enhancing Rural Public Transport Provision
}

Nagendra R. Velaga, John D. Nelson, Steve D. Wright, John H. Farrington University of Aberdeen, UK

\begin{abstract}
This paper explores the existing context of public transport provision in rural and remote areas illustrated with experience from Scotland. A critical review of existing Flexible Transport Services (FTS) in rural areas is provided and illustrated with selected case studies, with the objective of identifying the extent to which FTS can enhance the public transport offer. Findings confirm that FTS offers considerable potential to contribute to and support the public transport system in rural areas; however, the paper also identifies the many challenges in successful development or enhancement of FTS in rural areas.
\end{abstract}

\section{Introduction}

It is widely accepted that a basic problem with rural transport is the lack of opportunities available to access a necessary range of basic service outlets and amenities located in distant centers (Nutley 2003; Kamruzzaman and Hine 2011). Traditionally, for most trips in urban areas, users seeking an alternative to private car use will generally have a choice of several alternative transport modes ranging from a (relatively) low-cost fixed route and fixed schedule public transport service to a high-cost and comfortable private taxi providing door-to-door service. This range of transport supply may not be available for remote and sparsely populated rural 
areas, where population density is low. Often, these remote areas are provided with inadequate public transport options for most of the day. The definition and classification of urban and rural areas varies across the world and even within the UK. In this paper, we have considered a six-stage urban-rural classification by the Scottish Government that is based on settlement size and proximity to other bigger settlements (National Statistics 2010).

The need for transport services for socially disadvantaged groups (e.g., older adults, young, and disabled) in rural and remotely located areas is undeniable (Currie 2010). To a great extent, a well-organized public transport system in rural areas can enhance economic growth by improving social inclusion, accessibility, and mobility (Farrington and Farrington 2005). However, the characteristics of rural areas present some barriers to improving and developing public transportation. Examples of such characteristics are (1) rural dwellings are distributed over large areas, (2) population density is low and so potential passenger numbers are limited, and (3) level of demand is unpredictable. As a result, public transport systems in rural areas generally suffer from low and uncertain demand, and service coverage is very limited since the provision of frequent and widespread commercial public transport services is financially unjustifiable for the passenger numbers attainable.

A flexible and demand-responsive transport system has been identified as one of the promising solutions for widespread public transport in rural areas at times that are desired (Mulley and Nelson 2009). Over the last 20 years, many flexible transport services have been established; examples include shared taxicabs, shuttle vans, dial-a-ride services, paratransit services, ring-and-ride services, dial-up buses, lift shares, and car-clubs (Li and Quadrifoglio 2010). However, these are introduced largely as stand-alone services often to cater to a specific group of the population or to fill a specific need. There is little or no integration between services and so they may not offer a comprehensive network solution that could fill the gaps in conventional public transport in rural areas. More recent interest has centered on the extent to which collective or shared taxi services could be used to meet rural accessibility needs; the institutional, regulatory, and financial barriers to the introduction of such a scheme nationwide are explored by Mulley (2010).

FTS have been introduced both as part of the public transport mix and also to meet certain accessibility gaps. It is recognized that accessibility is a multi-dimensional concept relating to the ease with which individuals can reach destinations. Daniels et al. (2011) suggest that a number of different accessibility gaps can, therefore, exist, including a lack of service (spatial gap), inaccessible vehicles (physical gap), no 
service at the required time or the journey takes too long (time gap), passengers do not have the required information (information gap), services are too expensive (economic gap), and cultural/attitudinal issues around the use of public transport (cultural/attitudinal gap).

Evidence (Nelson and Phonphitakchai 2011) suggests that a well-designed flexible transport system can integrate different modes of transport to provide more user-centric, comfortable, and cost effective transport options by offering desired flexibility in choosing route, time, mode of transport, service provider, payment system, etc. Therefore, the main objective of this paper is to examine to what extent flexible and demand-responsive transport could be used to enhance public transport provision in rural areas and identify various challenges in implementing and enhancing FTS in rural and remote areas.

\section{Public Transport in Rural Areas: Case Study of Scotland}

Public transport in rural areas generally suffers from lack of service availability and infrastructure; services are infrequent, not easily accessible, and not connected to other modes of transport (Halden et al. 2002; Currie 2010). Recently, to enhance accessibility and connectivity for socially-disadvantaged groups the provision of enhanced public transport in remote areas is seen as one of several major rural development rationales (Currie 2010). Despite the efforts by the government, public transport provision in rural areas is still associated with poor service levels (Hurni 2006). This leads to problems of social exclusion particularly for the young, old, low-income, and disabled (Farrington and Farrington 2005; Shergold and Parkhurst 2010).

A study by Farrington et al. (1998) showed that in rural Scotland 89 percent of households had access to a car; moreover, cars were the main mode of transport for 77 percent of journeys, most rural areas were not connected by trains, and buses were used for 2 percent of journeys. Further, output from a survey of commuters who did not use public transport and used a personal car to access their work, study, and other basic amenities (such as hospitals and shopping centers) is shown in Figure 1 (Scottish Executive,2003). This survey was conducted with the age group of 16 and above, and the sample size was 31,031 randomly-selected households across Scotland. It was identified that in rural areas the most common reason for not using public transport is lack of service availability, followed by no direct route and inconvenience. 
In rural areas, if both a public transport service and access to a car are available for a journey, most passengers use a personal car; the main reason is lack of convenient public transport (Scottish Executive 2006a). In Figure 2, passenger views on the convenience of public transport in Scotland are shown. In rural Scotland, about 25 percent of passengers stated that public transport is very inconvenient. Conversely, about 50 percent of urban dwellers regarded public transport as being very convenient. According to the Scottish Household Survey conducted in 2009, only 2 percent of the rural population agreed that they have good public transport (National Statistics 2010).

The geographical classification of Scotland shows that remote rural areas occupy 69 percent of the total land and contain only 6 percent of the total Scottish population (National Statistics 2010). (Here, remote rural areas are defined as settlements of less than 3,000 people not within a 30-minute drive of a settlement of 10,000+ people.)

The road travel time by car to basic amenities (such as hospitals, and shopping centers) by postcode sector in Scotland is shown in Figure 3. From Figure 4, it is revealed that 73,61 , and 85 percent of remote rural population are located more than a 15-minutes drive time by public transport to reach the nearest GP, post office, and shopping facilities, respectively. Further, National Statistics (2010) revealed that about 29 percent of remote rural dwellers are more than 13 minutes and 20 percent are more than 26 minutes from their nearest bus stop.

Access to basic amenities through public transport is an essential requirement for rural dwellers, and the Scottish Government has recognized inadequate public transport as a major cause of social exclusion in remote rural areas (Scottish Executive 2001). Considering the conditions of public transport in remote areas of Scotland, in order to enhance social inclusion, accessibility, and mobility, there is a clear imperative to further improve transport provision. In the following section, the potential for demand-responsive and flexible transport services in rural and remote areas is reviewed. 
The Potential Role of Flexible Transport Services in Enhancing Rural Public Transport Provision

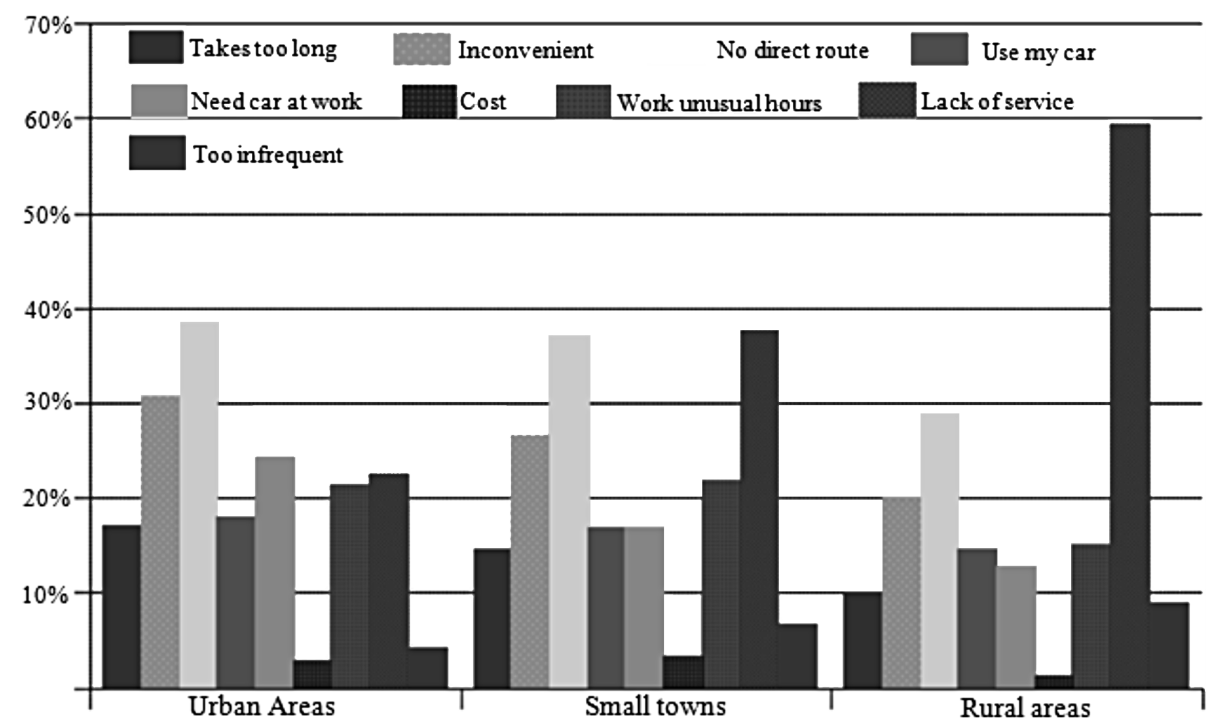

Source: Scottish Executive, 2003

Figure 1. Reasons for not using public transport

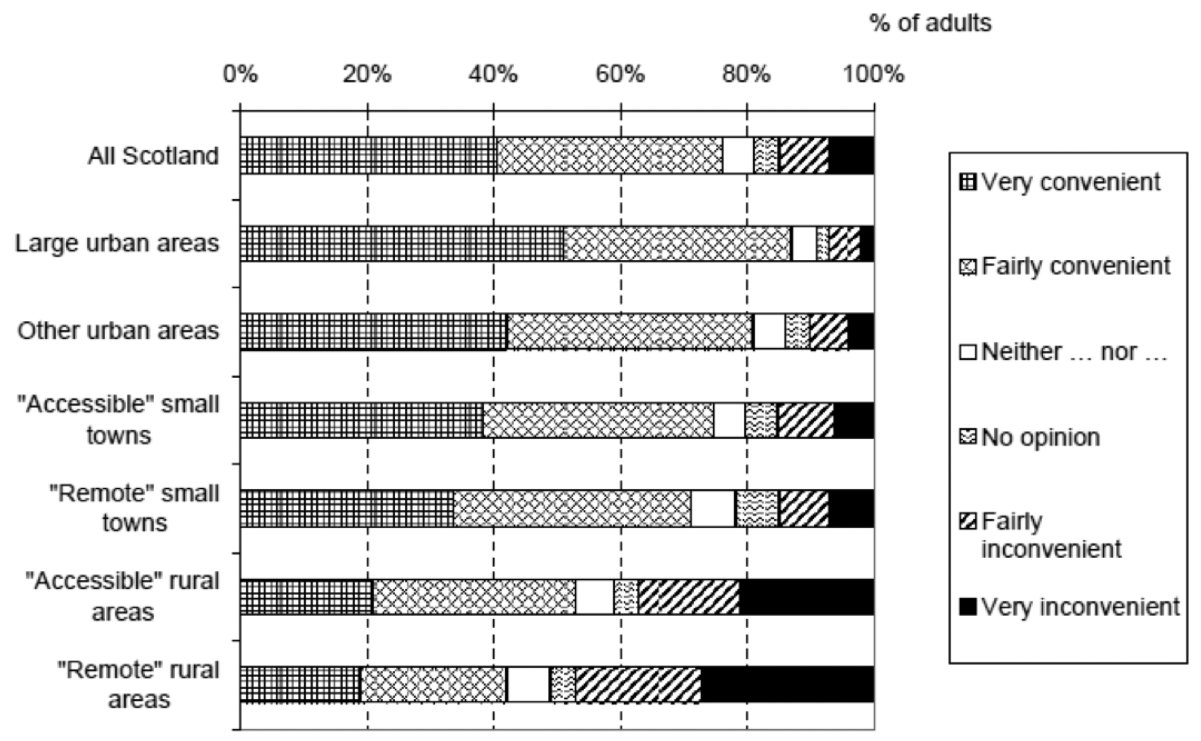

Source: Scottish Executive, $2006 a$

Figure 2. Views on the convenience of public transport in Scotland 


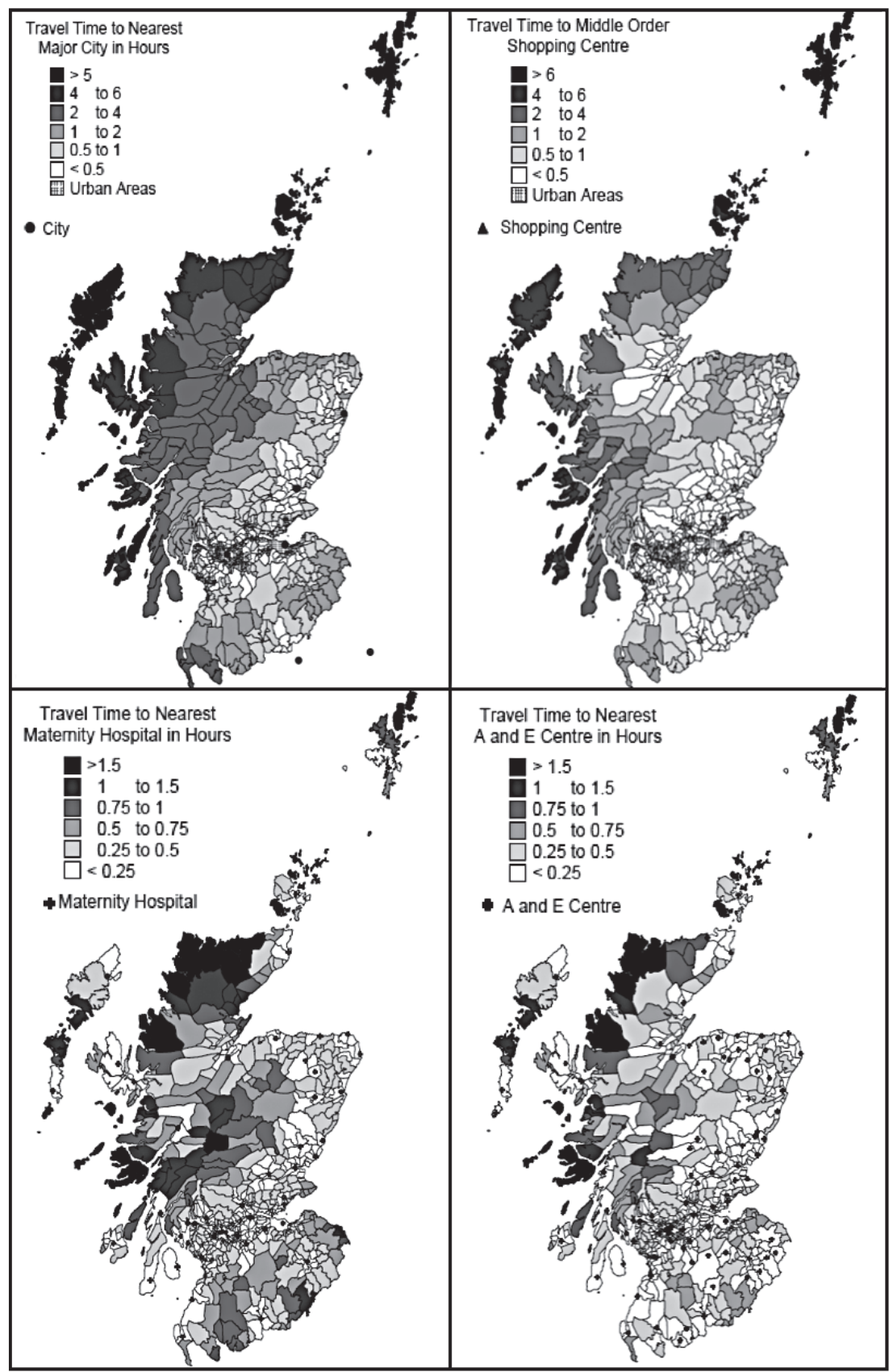

Source: Modified from Halden et al. (2002) and TACTRAN (2008)

Figure 3. Road travel time to basic amenities by postcode sector in Scotland 


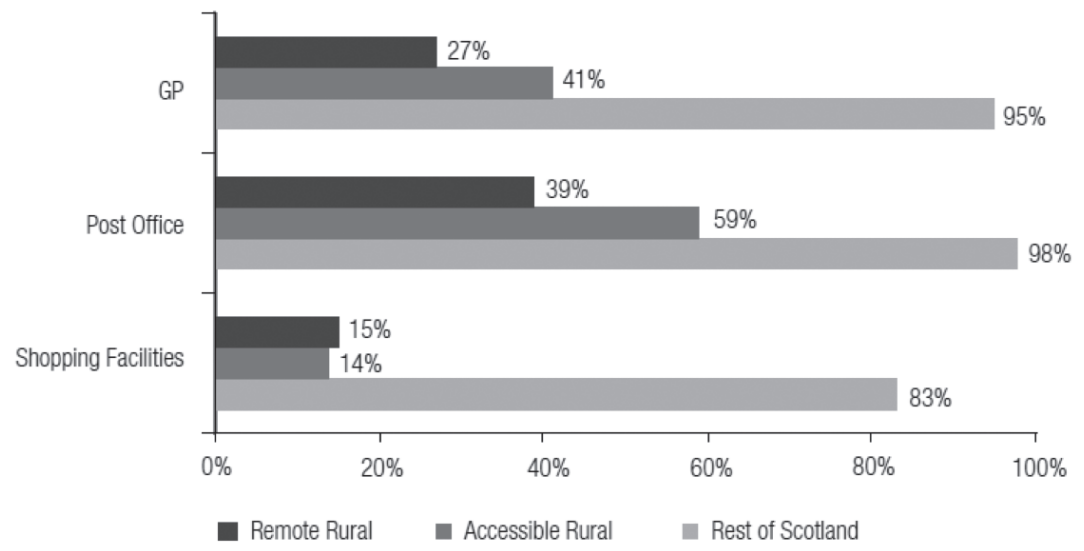

Source: National Statistics, 2010

\section{Figure 4. Percentage of population within 15-minute drive time by public transport service, by geographic area, 2009}

\section{Review of Flexible Transport Services in Rural Areas}

It seems unlikely that traditional fixed-route public transport in rural areas can be expected to provide a greater contribution than at present; the main barriers to this are identified as effective deployment in terms of both financial and carbon efficiency (Shergold and Parkhurst 2010). Recent studies suggest that one set of solutions for rural transport problems could be demand-led approaches such as demand-responsive flexible transport services, more formalized lift-giving, and community transport schemes (Mulley 2010). However, implementation of these demand-led approaches in rural areas has associated problems or limitations such as with technology, integration, and cost (Shergold and Parkhurst 2010).

A feasibility evaluation of FTS by Takeuchi et al. (2003) showed that FTS is one of the better solutions for transport problems in remote areas with low demand where conventional public transport systems are not appropriate. It was identified that FTS can improve mobility for special users (such as older adults and persons with disabilities) in rural areas because users are specific and demand density is small. Scott (2010) reviewed a specific FTS (Treintaxi services in Netherlands) that connects train stations and surrounding suburban and rural areas and found that Treintaxi services improve connectivity. In an international review, Enoch et al. (2004) found that fixed-route, fixed-schedule public buses are not ideally suited to serving dispersed rural areas with correspondingly low demand for public transport; and substitution of FTS can substantially replace conventional public 
transport services. However, there can be problems with lack of operators willing or able to participate in rural areas and in smaller settlements, leading to shortage of vehicles (Grosso et al. 2002). One possibility is to establish a service based on taxis in remote areas, although this may require considerable effort by local authorities (Enoch et al. 2004).

Brake and Nelson (2007) identified that in a deregulated public transport environment (such as the UK), more integrated flexible transport solutions (e.g., permitting the general public on education contract services, the use of taxis for shared public transport, and the provision of vehicles enabling access to work) based on people's real needs are required. Their research has examined the conditions that shape the provision of rural transport (such as demand pattern, rural accessibility) and analyzed the role of FTS in rural public transport using a case study of rural flexible transport schemes (Phone and Go services) in Northumberland, UK. Their study revealed that full integration of fixed-route public transport with FTS and links between stakeholders working in partnership would lead to enhancement of the rural transport system; similar findings have been demonstrated in urban and peri-urban locations (Nelson and Phonphitakchai 2011).

In 2008, the UK Commission for Integrated Transport (CfIT) examined the role of taxi-based demand-responsive transport services alongside conventional public transport in meeting rural accessibility needs (CFIT 2008). Its project conducted primary desktop research of publicly-available data, case studies, and stakeholder consultation of existing rural FTS across the UK and mainland Europe (see Figure 5). Their analysis concluded that demand-responsive FTS could be a promising solution to connect remote rural areas-with low population density and individuals with different requirements-and conventional public transport on main corridors. It was also found that integrated large-scale (regional) rural FTS with public transport can offer several benefits (for example, cost efficiencies, better services). From case studies, it was also noted that significant amounts of public subsidy/ funding are generally provided to improve and maintain public transport services in rural areas, though this has not generally been applied to rural FTS (CFIT 2008).

A recent review of 48 FTS schemes in England and Wales (Laws et al, 2009) found that in rural areas, 16 out of $25 \mathrm{FTS}$ require more than $€ 5$ subsidy per passenger trip, 8 out of 25 FTS require $E 2-£ 5$ subsidy per passenger trip, and one service is breaking even. Funding remains a key barrier to the introduction of FTS in rural areas. 


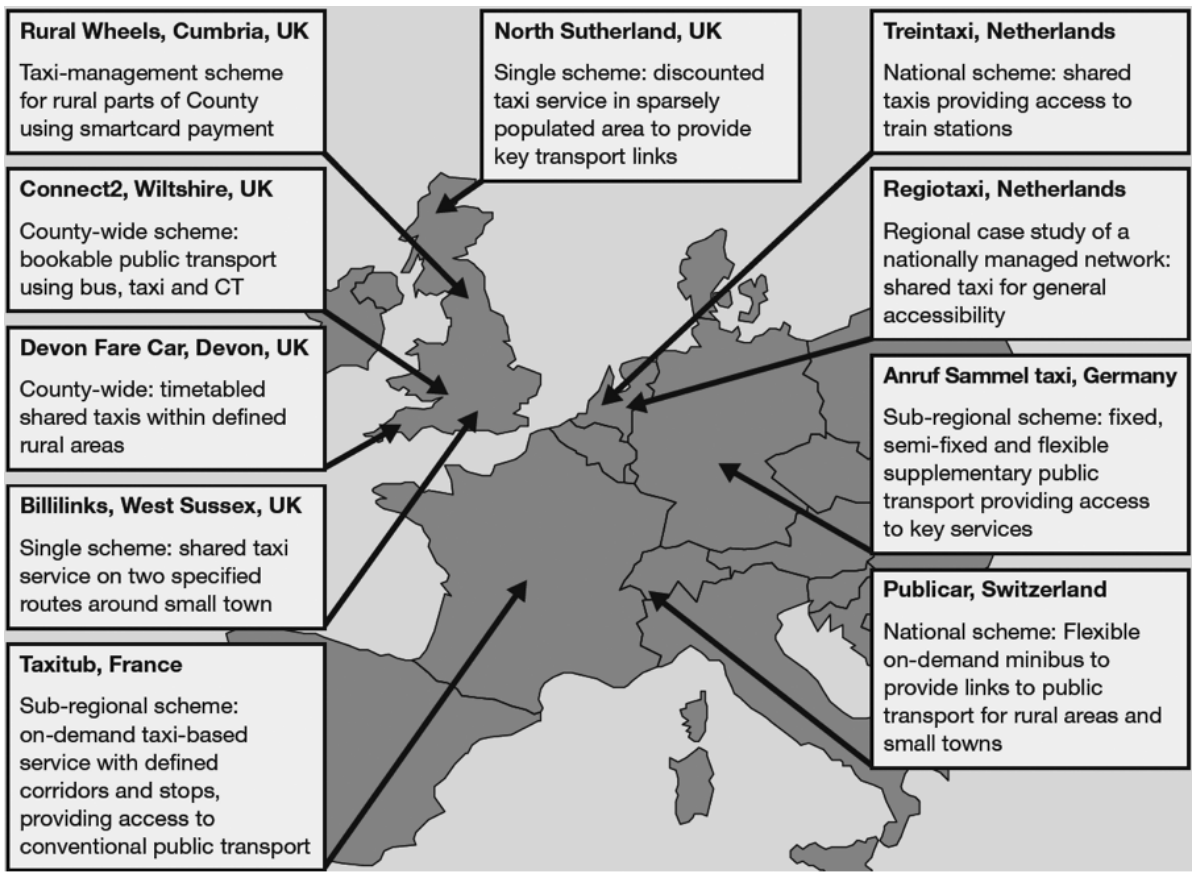

Source: CfIT, 2008

\section{Figure 5. Rural FTS case studies from UK and mainland Europe}

Within the UK, Mulley (2010) has analyzed the barriers to a nationwide shared taxi service to improve rural accessibility. Mulley concluded that while no institutional barriers have been identified within the deregulated framework for the introduction of collective taxi-based services, there is a complex regulatory system and an environment, through subsidy policy, that militates against the provision of a good quality taxi-based service, as observed in mainland Europe.

FTS has also been identified as attractive not only because it can potentially be integrated with, and complementary to, conventional public transport services but it is also considered as an option for reducing vehicle pollutants (such as CO, NOx and Particulate Matter) by optimal use of vehicles (Dessouky et al. 2003; Tuomisto and Tainio 2005; Diana et al. 2007). It should be noted, however, that such studies have not explicitly considered the rural context.

Hensher (2007) compared fixed-route public transport and informal flexible transport systems in some developing countries (e.g., the taxi van industry in South Africa). It was identified that FTS services offer the best transport service to con- 
nect main public transport corridors in low-density areas (suburban and rural); however, a greater focus should be placed on making these informal FTS safer and more reliable.

With this evidence, it can be inferred that FTS is widely seen as very effective in extending and augmenting public transport in rural areas and can become an accepted form of public transport. However, there are some issues (e.g., technological, financial, integration, shortage of vehicles, safety, and reliability) in developing and enhancing FTS in rural areas. The following section explores the experiences with FTS in rural Scotland and identifies various challenges and opportunities for the enhancement of existing FTS.

\section{Existing Experience with FTS in Rural Scotland}

Scotland has wide experience with FTS services, many of which operate in rural areas. In 2006, there were about 140 schemes in operation, and their spread-categorized by user type and operator type-is illustrated in Figure 6 .

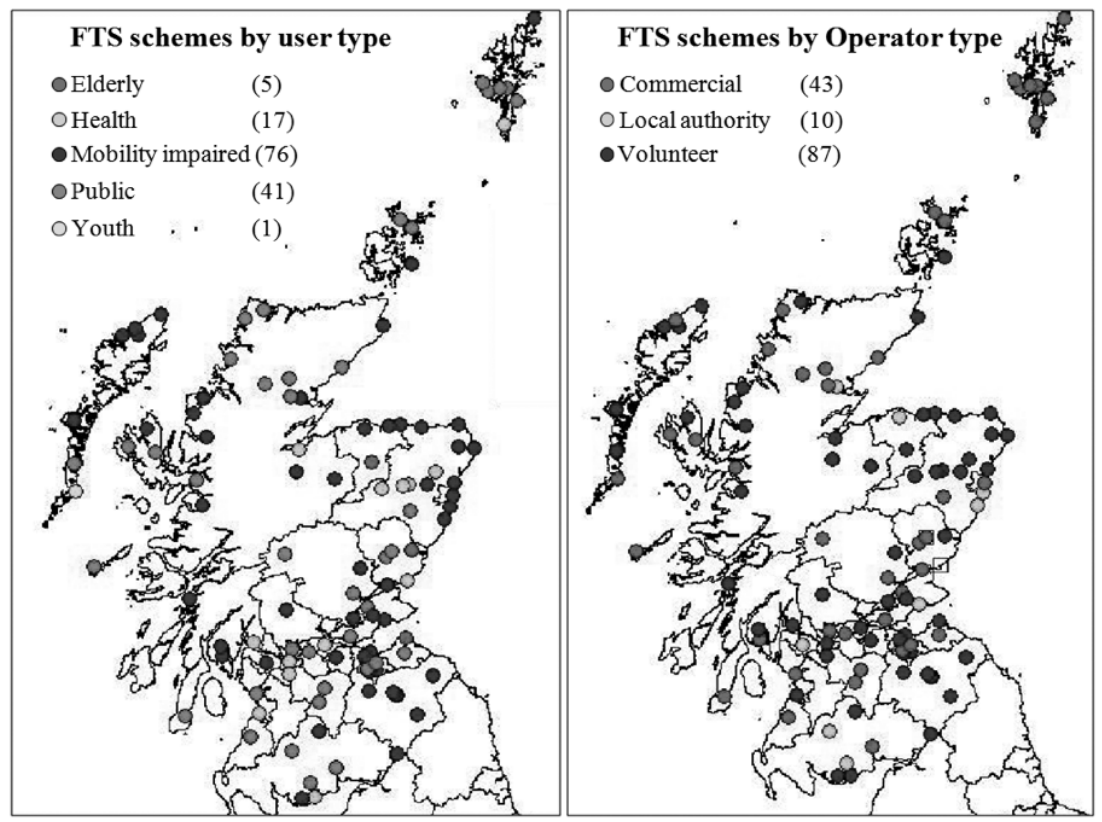

Source: Modified from Scottish Executive, $2006 b$

Figure 6. FTS schemes in Scotland 
From Figure 6, it can be observed that more than 50 percent of FTS are dedicated to mobility-impaired clients, with about 12 percent for general healthcare. None of the general healthcare FTS are established in the Scottish Highlands, where most of the land is rural and remote rural. There are five FTS schemes specifically for older adults and only one specifically for young passengers. It can be inferred from this that these groups could be perceived as potentially likely to be excluded. FTS schemes are operated/managed/commissioned by a range of different groups; it was also identified that most of the FTS in Scotland are community/volunteer and commercial type operation, and only about 7 percent are operated by local authorities.

Some examples of current and previous FTS schemes for the general public in rural Scotland are listed in Table 1.

Characteristics of the above FTS schemes in Scotland are further discussed here.

- The Gaberlunzie bus service in East Lothian was one of the earliest DRT services in rural Scotland. This service aimed to connect rural areas to the local towns of Haddington and Dunbar. Due to the high cost per passenger trip (E12), in 2001, this service was redesigned as a fixed route Monday-Saturday service (Scottish Executive 2006b).

- Flexible Transport Agency Services in Angus, which started in March 2002, were part of a European project funded by the EU-IST Programme (Eloranta and Masson 2004). The Angus FTS was not able to expand as a local agency for two principal reasons: (1) a variable pricing structure through the different operators (i.e., users did not necessarily have a constant price for a trip) due to the service being provided by different operators; and (2) users choosing to directly communicate with the operator for subsequent trips rather than through the Travel Dispatch Center (Scottish Executive 2006b).

- Midlothian Council's Dial a Journey service was established in 2003 to replace the conventional bus services withdrawn due to increasing costs and declining demand. The Dial a Journey service was run by local taxi operators (under taxi legislation), with conventional bus fares charged to passengers. The difference between taxi and bus fares was topped up by the council (Scottish Executive, 2006b). This service was stopped in March 2007 due to lack of funding.

- The Aberdeenshire A2B dial-a-bus is a demand-responsive door-to-door transport service introduced by Aberdeenshire Council in 2004 with assis- 


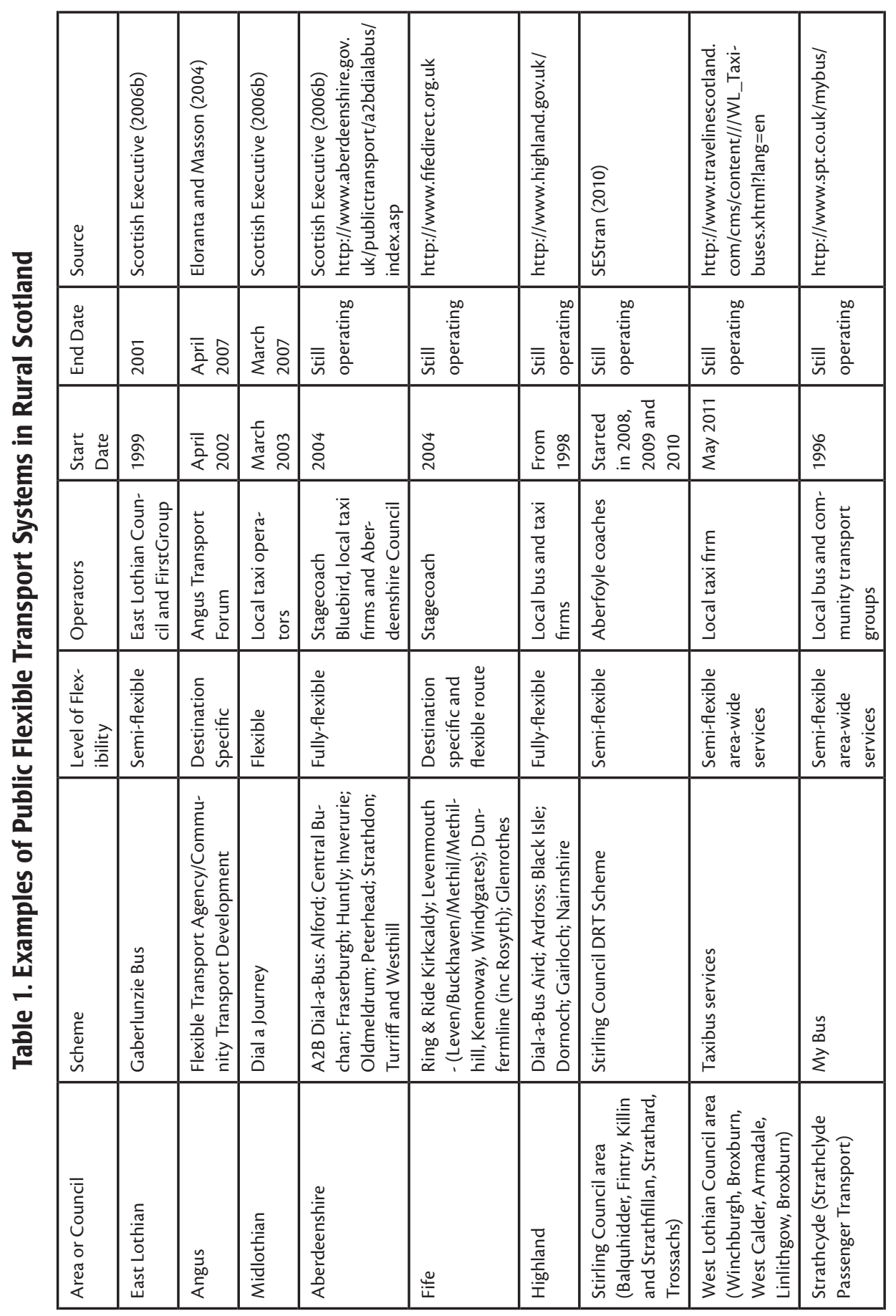


tance from the Scottish Executive. The services are fully flexible within defined areas and offer pick-up from the user's door, home road-end, or a recognized bus stop. Bookings are made through the Council-run booking office and can be made on the day of travel subject to availability.

- Fife Ring \& Ride is a door-to-door service that will take users anywhere within the local operating area. Bookings are made through the Council-run booking office the day before travel.

- Highland Dial-a-Bus provides an on-demand service within a defined area and time period and is available to all members of the public. Several of the services have replaced fixed-route buses. Bookings are made with the relevant provider the day before travel.

- The Stirling Council DRT Scheme is provided in rural areas where commercial or conventional bus operators are unable to provide bus services. Bookings are made with the provider the day before travel, but every effort is made to accommodate passengers making bookings at shorter notice.

- West Lothian Taxibus provides public transport to areas at times when no bus service is available. Bookings are made direct to the taxi operator the day before travel.

- MyBus is another of the earlier demand-responsive flexible transport services in Scotland designed to help all people living in rural areas with limited or no public transport. Additionally, it operates throughout metropolitan areas of Strathclyde. The services originally established as Dial-A-Ride are now offered on an open-access basis and booked via a common dispatch center.

The majority of the above services allow advanced booking only on the day before travel and use very little or no intelligent transport systems and advanced information and communication technology support. The Aberdeenshire A2B Dial-a-Bus and Strathclyde MyBus services are the exception and allow on-the-day booking supported by booking, scheduling, and dispatching software provided by Trapeze software. The Aberdeenshire service is also designed to provide interchange at selected points to the main public transport network, enabling travel outside the $A 2 B$ areas.

The examples above show that often FTS for the public are introduced either where no other public transport is available or to replace fixed-route bus services where demand is especially low or distant from the fixed route. There is an increasing trend towards using taxi operators to provide the services; this offers an already existing vehicle resource as well as a booking capability and, hence, offers signifcant reductions in operating costs. 
It is clear from the evidence that most of the rural FTS services in Scotland are on a small scale, isolated from each other as well as from other modes of transport (e.g., rail) and lacking strategic or regional planning. The recent study by CfIT (2008) on "A New Approach to Rural Public Transport" suggests there are likely benefits in terms of economies of scale to be gained from more coordinated services implemented across a wider area at the regional scale.

Other recent studies have identified that FTS plays an important and growing role in the spectrum of transport provision in rural Scotland (Juffs 2010). Juffs reports that local authorities have begun to seriously consider the role that FTS could have within local transport infrastructure provision. That realization has not generally emerged as a response to a specific local initiative or policy directive, but more so as bus services, previously regarded as stable and commercially viable, have been withdrawn, leaving local communities more isolated. Due to funding constraints, local authorities are now rarely able to provide support to replace withdrawn fixed-route services but may be able to support a lower-cost FTS, which may actually fill the gap left by more than one withdrawn fixed-route service. Considering the conditions of public transport in remote areas of Scotland and geographical conditions (e.g., rurality and widely spread population), further development and improvement of demand-responsive FTS is one of the promising solutions to enhance social inclusion, accessibility, and mobility. The following section provides various research challenges and opportunities.

\section{Challenges and Opportunities for the Development and Enhancement of FTS in Rural Areas}

There are certain problems involved in implementing/enhancing flexible transport in rural areas. This paper has considered evidence drawn from a review of various pilot FTS projects in rural Scotland, consultation with rural FTS scheme operators (e.g., Aberdeenshire Council), and presentation and targeted group discussion with FTS routing and scheduling software providers (e.g., Trapeze software) to identify various challenges and opportunities to develop and enhance FTS in rural areas. The following eight research challenges are identified.

1. Adopt a holistic approach (user, operator, and transport authority perspectives): There are three major players involved in a typical FTS: users, operators, and transport authorities. So far, researchers have generally concentrated either on user (passenger) perspectives or operator perspectives. For example, Finn (1999) and INVETE (2000) concentrated on passenger user requirements; Chen and Tsai (2008) and Garaix et al. (2010) developed 
optimization methods or techniques to maximize benefits to FTS operators. Often, the perspective of the transport authority is neglected. Moreover, considering requirements from all three components together can lead to a better outcome, such as the development of an intelligent decision making method that can fulfill user requirements, minimize cost, maximize operator benefits, and consider the regulations made by transport authorities.

2. A clear national level plan: It can be seen in Figure 6 that flexible transport services are generally planned and offered for limited areas by particular local authorities by targeting specific categories of people in the community. Developing a national-level plan for FTS, as advocated by Juffs (2010), may encourage better integration and coordination of services, leading to improved economic growth and increased social inclusion. However, development of a national FTS plan requires cooperation and coordination among different public authorities; it might be more difficult to achieve this, as different levels of government are often responsible for different aspects of public service delivery.

3. Integration of multiple modes: Integration of other modes of transport (e.g., rail) with flexible transport systems can improve the overall system performance (e.g., combined ticketing and payment system) and enable complete journey times and connections to be planned. Further research could develop a framework to support the integration of other modes of transport with FTS.

4. Service availability: Unlike urban areas, in rural areas it is very difficult to find transport service providers willing to cooperate to provide FTS. Due to the lack of service providers, often the service will be very costly or ineffective. Consider, as an example, an older adult passenger who wants to travel to an airport from a remote area that is far from the destination point; due to the lack of availability of transport service providers, the passenger may be recommended either to travel by taxi, which is very costly, or to travel on the previous day, which is inconvenient. Research could investigate further the mechanisms required to make better use of the available transport resource in remote rural areas (e.g., supported area-wide shared taxis schemes or building Community Transport capacity and capability).

5. Accessibility to remote areas: Rural dwellings are normally distributed over a large area. For example, about 20 percent of the UK's population live in rural areas distributed across about 80 percentof the land (House of Commons 2000; National Statistics 2010). It is very difficult to develop flexible 
transport systems that can pick-up and drop-off according to the individual user's desire. Some remote areas are not easily accessible. In some cases, these remote areas are not appropriately connected to a necessary range of basic service outlets and amenities (e.g., hospitals, schools) located in distant centers; this particularly affects socially-disadvantaged groups (e.g., older adults). Another research opportunity could be to look into the accessibility requirements of older adults, patients, and physically-challenged passengers in remote areas and the effect this has on FTS design and operation.

6. Understanding uncertainties and estimating transport demand in rural areas: Travel demand in rural areas is not easy to forecast. In the context of rural FTS, if transport demand models could be used to predict the potential transport requirements, then this would provide a very useful tool to aid the planning and scheduling of FTS vehicles.

7. Define appropriate evaluation methods and tools: There appears to be no fully accepted or implemented approach to the ex-ante or ex-post evaluation of FTS; this is a significant challenge, both for the planning and implementation of specific programs and schemes and for the understanding of benefits and costs. The method of Social Return on Investment (SROI) promises the ability to capture the wider, non-market benefits that FTS are designed to realize (see, e.g., Wright et al. 2009). While this speaks to a broader social agenda, transport policy makers and practitioners are also likely to require benefit-cost analysis of proposed FTS schemes.

8. Real-time communication to and from users: Communicating with passengers in real-time is also a major issue in remote areas. The principal mode of communication is telephone and rarely Internet. A more sophisticated passenger information "ecosystem" enabling all users to share information could enhance the benefits of integrated flexible transport services.

\section{Conclusions}

Public transport conditions in rural Scotland demonstrate that the main reasons for rural passengers using their personal car are lack of service availability, lack of direct route, and inconvenience. There is clearly a need to provide good quality transport services that are responsive to people's real needs, flexible, wellmarketed, well-integrated, and provide stable and reliable transport services for socially-disadvantaged groups that are not able to access conventional public transport and personal cars. This is especially pertinent in more rural areas. From 
this study, it was identified that Flexible Transport Services (FTS) can be a promising solution for developing transport solutions, particularly in rural and remote areas where public transport is not active.

In rural Scotland, FTS has been shown to be a good option for filling gaps in public transport through replacing withdrawn fixed-route bus services at a lower cost or by offering public transport in areas where commercial or conventional bus operators are unable to provide bus services. However, most of the existing Scottish rural flexible transport has limitations, such as small-scale operations, isolation from other modes of transport, targeting only specific categories of people in the community, not allowing booking on day of travel, and use of very little or no intelligent transport systems and advanced information and communication technology support. Removing these limitations could improve the transport conditions in rural areas and enhance mobility and connectivity and, thereby, social inclusion.

In this paper, associated problems involved in implementing/enhancing flexible transport in rural areas are discussed. Through the evidence drawn from a review of rural FTS projects, consultation with rural FTS scheme operators, and presentation and targeted group discussion with FTS routing and scheduling software providers (e.g., Trapeze software) various research challenges and opportunities are identified to develop and enhance FTS in rural areas. These key research challenges include (1) considering user, operator, and transport authority perspectives concurrently; (2) developing a national level FTS plan for rural areas; (3) integrating with different transport modes; (4) addressing some issues related to service provider availability; (5) better appreciation of accessibility and connectivity needs of socially-disadvantaged groups in remote areas; (6) better understanding of uncertainties with transport supply and demand in rural areas; (7) defining appropriate evaluation methods and tools; and (8) enhancing real-time communication with FTS users in rural areas.

\section{Acknowledgments}

This research is supported in part by an award made by the RCUK Digital Economy programme to the dot.rural Digital Economy Hub; award reference: EP/G066051/1. 


\section{References}

Brake, J., and J. D. Nelson. 2007. A case study of flexible solutions to transport demand in a deregulated environment. Journal of Transport Geography 15: 262-273.

CfIT. 2008. A new approach to rural public transport. Commission for Integrated Transport (CfIT) report. Available at: http://www.scribd.com/doc /25768741 /A-New-Approach-to-Rural-Public-Transport.

Chen, S., and F. Tsai. 2008. Generating fuzzy rules from training instances for fuzzy classification systems. Expert Systems with Applications 35: 611-621.

Currie, G. 2010. Quantifying spatial gaps in public transport supply based on social needs. Journal of Transport Geography 18: 31-41.

Daniels, R., C. Mulley, R. Teal, J. Nelson, and S. Wright. 2011. Barriers to implementing flexible transport services: An international comparison of the experiences in Australia, Europe and North America. Submitted to Research in Transport and Business Management.

Dessouky, M., M. Rahimi, and M. Weidner. 2003. Jointly optimizing cost, service, and environmental performance in demand-responsive transit scheduling. Transportation Research D 8: 433-465.

Diana, M., L. Quadrifoglio, and C. Pronello. 2007. Emissions of demand responsive services as an alternative to conventional transit systems. Transportation Research Part D 12: 183-188.

Eloranta, P., and B. Masson. 2004. The FAMS approach in Angus. In: Ambrosino, G., M. Boero, J. D. Nelson, and M. Romanazzo (Eds.), Infomobility Systems and Sustainable Transport Services. Rome: ENEA, 269-277.

Enoch, M., S. Potter, G. Parkhurst, and M. Smith. 2004. INTERMODE: Innovations in demand responsive transport, Final Report. http://design.open.ac.uk/potter/ documents/ INTERMODE.pdf

Farrington, J., D. Gray, S. Martin, and D. Roberts. 1998. Car dependence in rural Scotland. Available: http://www.scotland.gov.uk/Publications/1998/12/ c9440b07-a28b-4c80-bbb6-f2d7bb815fa9, accessed 03/16/2011.

Farrington, J., and C. Farrington. 2005. Rural accessibility, social inclusion and social justice: Towards conceptualisation. Journal of Transport Geography 13: 1-12. 
The Potential Role of Flexible Transport Services in Enhancing Rural Public Transport Provision

Finn, B. M. 1999. Requirements of users of DRT systems, SAMPLUS Project Deliverable No. 3, Dublin.

Garaix, T., C. Artigues, D. Feillet, and D. Josselin. 2010. Vehicle routing problems with alternative paths: An application to on-demand transportation. European Journal of Operational Research 204: 62-75.

Grosso S, J. Higgins, J. Mageean, and J. Nelson. 2002. Demand responsive transport: Towards best practice in rural applications. European Transport Conference, Homerton College, Cambridge, 9-11 September.

Halden, D., J. Farrington, and A. Copus. 2002. Rural accessibility. Scottish Executive Central Research Unit report. Available at: http://www.scotland.gov.uk/ Resource/Doc/ 46922/0030639.pdf, accessed 3/16/11.

Hensher, D. A. 2007. Bus transport: Economics, policy and planning. Research in Transport Economics 18. Available at: http://www.sciencedirect.com/science/ article/pii/ S07398 85906180014.

House of Commons, 2000. Environment, Transport and Regional Affairs Committee Seventh Report-Rural White Paper. House of Commons: London.

Hurni, A. 2006. Transport and social exclusion in Western Sydney. University of Western Sydney and Western Sydney Community Forum project report. Available at: http://www.wscf.org.au/uploads/File/Transport_disadvantage_ report_web.pdf.

INVETE project. 2000. User needs and requirements for the in vehicle terminal, Deliverable D2.

Juffs, B. 2010. A further review of demand responsive transport in Scotland. Transport for Scotland report. Available at: ttp://www.transportscotland.gov.uk/ files/ documents /public-transport/Demand_Responsive_Transport.pdf.

Kamruzzaman, M., and J. Hine. 2011. Participation index: A measure to identify rural transport disadvantage? Journal of Transport Geography 19: 882-899.

Laws, R., M. Enoch, S. Ison, and S. Potter. 2009. Demand responsive rransport: A review of schemes in England and Wales. Journal of Public Transportation 12: 19-37.

Li, X., and L. Quadrifoglio. 2010. Feeder transit services: Choosing between fixed and demand responsive policy. Transportation Research Part C 18: 770-780. 
Mulley, C. 2010. Promoting social inclusion in a deregulated environment: Extending accessibility using collective taxi-based services. Research in Transportation Economics 29:1: 296-303.

Mulley, C., and J. D. Nelson. 2009. Flexible transport services: A new market opportunity for public transport. Research in Transportation Economics 25: 39-45.

National Statistics, 2010. Rural Scotland key facts 2010. The Scottish government report. Available at: http://www.scotland.gov.uk/Resource/ Doc/324955/0104729.pdf, accessed 03/16/2011.

Nelson, J. D., and T. Phonphitakchai. 2012. An evaluation of the user characteristics of an Open Access DRT service. Research in Transportation Economics, 34, 54-65.

Nutley, S. 2003. Indicators of transport and accessibility problems in rural Australia. Journal of Transport Geography 11: 55-71.

Scott, R. A. 2010. Demand responsive passenger transport in low-demand situations. NZ Transport Agency Research Report No. 425.

Scottish Executive. 2001. Evaluation of the rural transport fund. Government of Scotland. Available at: http://www.scotland.gov.uk/Resource/ Doc/156511/0042024.pdf.

Scottish Executive. 2003. Social focus on urban rural Scotland. Government of Scotland. Available at: http://www.scotland.gov.uk/Resource/Doc/47095/0029282. pdf , accessed 06/17/2011.

Scottish Executive. 2006a. Statistical bulletin on transport services. Government of Scotland. Available at: http://www.scotland.gov.uk/Resource/ Doc/88749/0021176.pdf, accessed 03/18/2011.

Scottish Executive. 2006b. Review of demand responsive transport in Scotland. Government of Scotland. Available at: http://www.scotland.gov.uk/Resource/ Doc/ 118404/0029110.pdf.

SEStran. 2010. Feasibility of DRT in East Lothian. Final Report. Available at http:// www.sestran.gov.uk, accessed 08/01/2011. 
The Potential Role of Flexible Transport Services in Enhancing Rural Public Transport Provision

Shergold, I., and G. Parkhurst. 2010. Operationalising "sustainable mobility": The case of transport policy for older citizens in rural areas. Journal of Transport Geography 18: 336-339.

TACTRAN. 2008. Buses strategy and community and demand responsive transport action plan: Audit of policies, services and infrastructure, final report. Available at: http://www.tactran.gov.uk/documents/3AuditReport_207817_FINAL.pdf, accessed on 08/01/2011.

Takeuchi, R., F. Nakamura, I. Okura, and H. Hiraishi. 2003. Feasibility study on demand responsive transport systems. Journal of the Eastern Asia Society for Transportation Studies 5: 388-397.

Tuomisto, J. T., and M. Tainio. 2005. An economic way of reducing health, environmental, and other pressures of urban traffic: A decision analysis on trip aggregation. BMC Public Health 5: 123.

Wright, S., J. D. Nelson, J. M. Cooper, and S. Murphy. 2009. An evaluation of the Transport to Employment (T2E) scheme in Highland Scotland using Social Return on Investment (SROI). Journal of Transport Geography 17(6): 457-467.

\section{About the Authors}

Dr. NAGendRA VelaGA (n.r.velaga@abdn.ac.uk) is Research Fellow in Intelligent Transport Systems at the dot.rural Digital Economy Hub, University of Aberdeen, UK.

Professor John Nelson (j.d.nelson@abdn.ac.uk) holds the Sixth Century Chair of Transport Studies and is Director of the Center for Transport Research, University of Aberdeen, UK.

Dr.Steve Wright (s.d.wright@abdn.ac.uk) is a Research Fellow in the Center for Transport Research, University of Aberdeen, UK.

Professor John FARRIngton (j.farrington@abdn.ac.uk) is Chair of Transport and Environment and Director of the dot.rural Digital Economy Hub, University of Aberdeen, UK. 